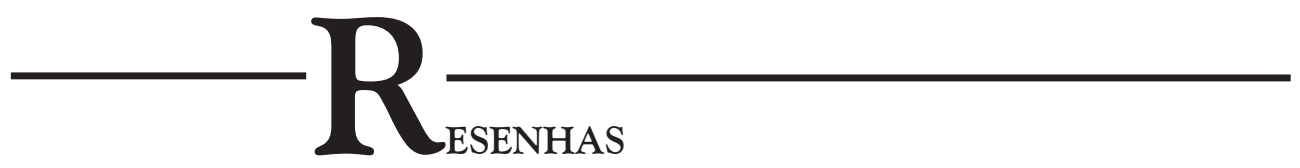

BARBOSA, Francirosy Campos. Hajja, Hajja: a experiência de peregrinar. São Bernardo do Campo: Ambigrama, 2021, 109pp.

Liza Dumovich

Núcleo de Estudos do Oriente Médio/UFF

Niterói - Rio de Janeiro - Brasil

https://orcid.org/0000-0001-9804-7234

\title{
REVElAÇÕES DO SELF: UMA AUTOETNOGRAFIA A PARTIR DO HAJJ
}

O Hajj, ou peregrinação a Meca, é um dos pilares do islã - juntamente com a profissão de fé (shahada), a oração (salat), o jejum (sawm) e a doação (zakat) - e deve ser realizado por todo muçulmano, seja homem ou mulher, pelo menos uma vez na vida, desde que tenha condições físicas e econômicas. A experiência do Hajj se compõe de três momentos rituais: o antes, o durante e o depois da viagem.

Os preparativos antes da partida envolvem uma série de exigências, tais como a realização de rituais burocráticos e administrativos que podem levar meses, a mobilização de uma soma inalcançável para a maioria dos muitos muçulmanos e uma dose de sorte, às vezes interpretada como obra do destino (Hammoudi 2005; Boissevain 2013). O ciclo ritual se compõe de diferentes etapas e envolve um percurso por Meca e seus arredores. Durante esse grande ritual coletivo, o peregrino vive a experiência religiosa, reafirma a sua identidade muçulmana e o seu pertencimento à 
umma, a comunidade global dos muçulmanos, materializada nos mais de 2 milhões ${ }^{1}$ de fiéis de todas as partes do mundo reunidos em Meca. Depois de cumprir com essa obrigação religiosa, os muçulmanos são chamados de Hajji ou Hajja, uma distinção que expressa o capital simbólico adquirido por quem realiza o mais disputado, árduo e dispendioso dos rituais islâmicos. Relatos orais, escritos ou na forma de fotografias costumam se seguir ao retorno do peregrino (Pinto 2019).

Talvez o mais célebre relato da peregrinação a Meca seja o de Sir Richard F. Burton (1964), diplomata e orientalista britânico que empreendeu essa jornada disfarçado de muçulmano em 1853. Mais recentemente, a etnografia do antropólogo muçulmano Abdellah Hammoudi (2005), que fez o Hajj em 1999, revela uma experiência da peregrinação marcada por análises e reflexões teóricas. Para além dos relatos pessoais, diversas pesquisas discutem o Hajj enquanto noção e prática, seja do ponto de vista histórico ou antropológico (e.g. Metcalf 1990; Boissevain 2013; Chiffoleau 2015). Paulo Pinto (2019) analisa, especificamente, as práticas de peregrinação entre muçulmanos brasileiros, dos quais os convertidos compõem uma importante parcela. De acordo com Pinto (:99), o número de muçulmanos que fazem o Hajj a partir do Brasil varia entre 100 e 150 ao ano, entre homens e mulheres. Em 2017, Francirosy Campos Barbosa foi uma delas.

A estrutura narrativa de Hajja, Hajja se inicia com uma apresentação da interseção dos pertencimentos acadêmico e religioso da autora, que enfatiza os seus 20 anos de pesquisa em comunidades muçulmanas, a conversão ao islã em 2013, um pós-doutorado no esforço de construir um lugar legítimo na academia como muçulmana e, finalmente, o cumprimento do quinto pilar do islã, a peregrinação a Meca, em 2017 - quando a dra. se torna, também, Hajja. Em seguida, Barbosa discute as ambiguidades e dificuldades das quais não pode se furtar na construção de uma metodologia de pesquisa. E é por meio do método autoetnográfico que Barbosa propõe uma reflexão sobre ritual a partir das suas próprias percepções do sensível, tendo como contexto o ciclo ritual do Hajj e como recorte uma "perspectiva feminina" (:41).

O núcleo da narrativa se divide em seis seções que descrevem o antes, o durante e o depois da viagem. Os preparativos se iniciam um mês antes da sua partida para a Arábia Saudita, quando ela recebe a ligação telefônica que anuncia a aprovação da sua participação no Hajj 2017. Esse período foi ocupado por estudos sobre o Hajj, mas também por rituais administrativos e burocráticos. Nesse período liminar, Barbosa experienciou uma sensação de morte, que ela interpretou como a morte simbólica que antecede a transformação da muçulmana pelo processo ritual.

Uma vez no destino, Barbosa nos conduz a Medina, cidade caracterizada pelo comércio e que abriga a Mesquita do Profeta. Em seguida, ela nos leva a Meca, onde o ciclo ritual se inicia, propriamente, e cujo rito central é a circumbulação da Caaba. ${ }^{2}$

1 Em 2017, ano em que a autora realizou a peregrinação, o número total de peregrinos foi de 2.352.122, de acordo com documento emitido pelo governo saudita. Disponível em: https:/www.stats.gov.sa/sites/default/files/haj_40_ en.pdf.

2 A Caaba é o ponto focal do Hajj e o maior centro sagrado do islã, para onde os muçulmanos de todo o mundo se direcionam durante as orações. Situada na Grande Mesquita de Meca, a Caaba é uma estrutura cúbica que 
Ela segue, então, para Mina, cidade onde os peregrinos se concentram todos ao mesmo tempo e a experiência da coletividade se intensifica. O ciclo ritual termina em Arafat, onde o Profeta Muhammad proferiu o seu último sermão. A descrição das condições concretas da peregrinação constrói ambientes cheios de cores, cheiros e sons; enquanto a descrição das práticas rituais acrescenta uma dimensão espiritual às imagens narradas.

$\mathrm{O}$ argumento central de Barbosa é que a força da experiência religiosa produzida pelo ritual do Hajj transforma, de algum modo e em algum nível, a peregrina. "Você encontra no Hajj o que vai buscar", a autora repete aqui e ali. Depois da viagem, por meio do esforço de descrever e codificar em texto a sua experiência, a autora parece encontrar o que foi buscar no Hajj: a reconfiguração do seu self religioso e a reafirmação da sua identidade muçulmana.

No entanto, a proposta de Barbosa pouco supera uma autobiografia. Enquanto há uma discussão teórica e metodológica na primeira parte do livro, a descrição do ciclo ritual carece de conceitos analíticos e, logo, de uma análise antropológica. O que o leitor encontra é uma coleção de memórias da peregrina. Se a autoetnografia é um método que usa experiências pessoais como ponto de partida para uma análise antropológica (Wulff 2021), é preciso indagar qual é o interesse etnográfico de um relato de sentimentos, emoções e percepções desprovido de um aporte teórico e conceitual.

A ausência de uma interlocução com conceitos analíticos se reflete nas contradições que marcam o discurso da autora. Por um lado, Barbosa situa sua pesquisa na interseção entre islã e gênero, além de acionar repetidamente a categoria "feminino", que ela não conceitualiza, para indexar sua "perspectiva". Por outro lado, ela sugere que as mulheres necessitam de orientação, seja de um marido, de Muhammad ou de Deus (:65). De fato, ao longo do texto, seus discursos e práticas legitimadores da autoridade religiosa de shaykhs (líderes religiosos) contrastam com seus discursos reprovadores das condutas de outras mulheres peregrinas (por exemplo, nas páginas 59-61, 79 e 92). Quer como antropóloga, quer como muçulmana, Barbosa acaba por reproduzir noções e práticas hierarquizantes entre homens e mulheres.

O texto se beneficiaria de um diálogo com a literatura antropológica sobre o Hajj ou mesmo outras peregrinações muçulmanas. A trivialidade de certos relatos, tais como quando a autora escovou os dentes ou tomou banho, torna um tanto angustiante a ausência de análises dos símbolos do ritual e seus papéis sociais e políticos, das tensões geradas pela normatividade do programa do Hajj e dos efeitos das inflexões wahhabitas ${ }^{3}$ que se impõem pelo controle saudita - para citar alguns temas recorrentes na produção acadêmica sobre o Hajj.

Contudo, as limitações mencionadas anteriormente não obscurecem a relevância e as potencialidades do livro. Desde a década de 1990, a peregrinação a lugares sagrados do islã (Arábia Saudita, Irã e Iraque) tem se tornado uma prática significativa entre os muçulmanos brasileiros (Pinto 2019); entretanto, um relato pessoal

simboliza a "Casa de Deus" na Terra e a aliança entre Deus e Abraão, confirmada por Muhammad. Como parte do ciclo ritual do Hajj, os peregrinos dão sete voltas no sentido anti-horário em torno da Caaba.

3 Wahhabismo é a corrente religiosa dominante na Arábia Saudita, cuja interpretação do islã é bastante restritiva em relação à presença e atuação das mulheres no espaço público. 
do Hajj era, até a publicação de Hajja, Hajja, inexistente na academia brasileira. Como o Hajj é uma peregrinação interdita a não muçulmanos, uma etnografia desse ritual dependeria de um(a) antropólogo(a) nativo(a).

Por último, mas não menos importante, a autoetnografia de Barbosa permite compreender a peregrinação como um rito de passagem que, além de reafirmar a identidade religiosa do peregrino, materializa a ideia de comunidade religiosa global e produz disposições emocionais corporificadas que conectam o peregrino à sua religião. Ademais, a publicação da experiência de Barbosa viabiliza a produção de comparações e confrontações com experiências de outras peregrinas, além de ser o arranque para a construção de uma memória coletiva sobre a experiência do peregrinar entre muçulmanas e muçulmanos no Brasil.

\section{Referências}

BOISSEVAIN, Katia. (2013), "Preparing for the Hajj in Contemporary Tunisia: Between Religious and Administrative Ritual”. In: B. Dupret, T. Pierret, P. G. Pinto e K. Spellman-Poots (ed.). Ethnographies of Islam: Ritual, Performances and Everyday Practices. Edinburgh: Edinburgh University Press, 2. ed.

BURTON, Richard F. (1964), Personal Narrative of a Pilgrimage to Al-Madina and Meccah. New York:

Dover Publications, Inc.

CHIFFOLEAU, Sylvia. (2015), Le Voyage à La Mecque: un pèlerinage mondial en terre d'Islam. Paris: Belin. HAMMOUDI, Abdellah. (2005), Une saison à la Mecque: récit de pèlerinage. Paris: Le Seuil.

METCALF, Barbara D. (1990), "The pilgrimage remembered: South Asian accounts of the hajj”.

In: D. F. Eickelman \& J. Piscatori (ed.). Muslim Travellers: pilgrimage, migration, and the religious imagination. London: Routledge.

PINTO, Paulo G. (2019), "Pilgrimage and Transnational Religious Imagination in the Muslim

Communities of Brazil”. In: B. Rahimi e P. Eshaghi (ed.). Muslim Pilgrimage in the Modern World.

Chapel Hill: University of North Carolina Press.

WULFF, Helena. (2021), "Writing Anthropology". In: F. Stein, S. Lazar, M. Candea, H. Diemberger, J. Robbins, A. Sanchez \& R. Stasch (ed.). The Cambridge Encyclopedia of Anthropology. Cambridge: Cambridge University Press.

\section{Liza Dumovich* (lizadumovich@gmail.com)}

* Pesquisadora associada ao Núcleo de Estudos do Oriente Médio (NEOM) da Universidade Federal Fluminense, Niterói, Rio de Janeiro, Brasil. Doutora em Antropologia pelo PPGA/UFF. Coeditora da revista Diáspora - Oriente Médio $\mathcal{E}$ Norte da África e autora do livro Ya habibi: conversão feminina ao islã no Rio de Janeiro. Rio de Janeiro: Ponteio/EdUCAM, 2016. 